\title{
ASSESSMENT OF TOOTH SHADE AFTER DE-AND RE-HYDRATION DURING CLINICAL RESTORATIVE PROCEDURES: A RANDOMIZED CLINICAL TRIAL
}

\author{
Shereen Hafez ${ }^{*}$ and Sameh Abou-Steit**
}

\begin{abstract}
Objectives: this study was aimed to assess any tooth colour change resulting from dehydration due to rubber dam application and the required time for any change to recover to baseline. Furthermore, to evaluate the quality of change and the affected areas of the teeth.

Materials and methods: Ten Participants with intact maxillary central incisors were recruited from the clinic of conservative dentistry. The age was ranging from 20 to 55 years with a mean age of 30.5 years. The inclusion criteria were unrestored intact maxillary central incisors without tooth bleaching performed over the past year. Exclusion criteria were the existence of any fixed orthodontic appliance or retainers or restorations on central incisors. Patients were randomized after performing polishing of their teeth. The VITA Easyshade spectrophotometer was used for evaluating tooth shade in this study. A baseline measurement was taken of the test tooth and then at $10 \mathrm{~min}$ and $30 \mathrm{~min}$. Further spectrophotometric measurements of the test tooth were done at,40 min and 60 min during rehydration. Data was collected from the Easyshade as CIE L*a*b* coordinates, chroma $(\mathrm{C})$, hue $(\mathrm{H})$ and $\triangle \mathrm{E}$. For statistical analysis, ANOVA was used to study the changes due to de- and re-hydration processes at the significance level $\mathrm{P} \leq 0.05$.
\end{abstract}

Results: Color change $(\Delta \mathrm{E})$ : there was a statistically significant change in mean $(\Delta \mathrm{E})$ values (P-value $<0.001$, Effect size $=0.602)$. Pair-wise comparisons revealed that there was no statistically significant change in mean $(\Delta \mathrm{E})$ values from 10 to 30 minutes. From 30 to 40 minutes, there was a statistically significant decrease in mean $(\Delta \mathrm{E})$ value followed by non-statistically significant change from 40 to 60 minutes (A statistically significant decrease after rehydration).

Conclusions: It is necessary to develop standardized, reproducible imaging modalities and objective image analysis methods. It should be highlighted that a systematic consideration of the dynamic light interaction within the coronal structures is essential for selecting proper value and chromaticity for restorative materials that is mandatory to obtain the successful esthetic restorations. Within the limitations of the present clinical trial, there is an obvious change in teeth shade upon dehydration that was assessed clinically by spectrophotometer. It is highly recommended by the clinicians to wait more than $60 \mathrm{~min}$ in order to properly assess color match, or to carry out the shade matching procedure on another dental visit. Dental shade matching procedures should be performed before the teeth exposure to dehydration to avoid shades mismatch that may not be satisfactory and would require modification or even remake of restorations.

KEYWORDS: esthetic, tooth shade, spectrophotometer, tooth dehydration, tooth rehydration, color assessment

\footnotetext{
* Assistant Professor of Conservative Dentistry, Faculty of Dentistry, Cairo University.

** Lecturer of Fixed Prosthodontics, Faculty of Dentistry, Ahram Canadian University.
} 


\section{INTRODUCTION}

From the architectural point of view, the smile represents approximately $60 \%$ of the weight of the face that may have a visual impact subconsciously on people we meet. Statistics performed by the American academy of cosmetic dentistry survey (AACD) in 2017 revealed that a high value is considered on a patient smile. Furthermore, the populations have an increased awareness of the role teeth play in appearance; hence, patients' expectations of aesthetics in contemporary dentistry are ever increasing. Here comes the importance of performing esthetic dentistry that is highlighted as reproducing natural looking teeth by generating perfect esthetic restorations that represents a great challenge for long time due to many materials' limitations affecting shade integration or surface quality, as well as possibly color stability.

Patient frustration regarding tooth colour was the main aim in a survey concerned with esthetic appearance. ${ }^{(1)}$ Thus precise shade measurement gathered with proper communication of tooth colour is essential to a clinically prosperous aesthetic outcome. ${ }^{(2)}$ It is compulsory that clinicians should have better understanding for dynamic light interaction with tooth structures together with the proper histoanatomic principles for proper material and shade selection during any restorative procedure whether direct or indirect. The structural configurations of the tooth formulate a complex optical medium for light when passing through the enamel tissue to dentin traversing the intervening dentino-enamel complex in terms of opacification which is the complete reflection of light as well as gradient between transparency which is the complete light transmission. ${ }^{(3)}$ Furthermore, this behavior is not constant through time however it changes over the years, as tissues change in composition and morphology. A better understanding of active aging of tooth structures is a crucial for success when selecting the proper value and chromaticity for any restorative materials.
${ }^{(4,5)}$ Hence, clinicians as well as technicians should have enough training sessions for proper selection of tooth shade. Thus to achieve a clinically accepted esthetic outcomes, there are four main contributing factors are: Dynamic Light Interaction, Histo-anatomical Features, Smilography and the 9 Elements of visual synthesis ${ }^{(3)}$

In dental practice, one of the real challenge facing the clinicians is the accurate reproduction of the optical characteristics of the intact tooth, outstanding to the inherent translucency enamel, dentin and the intervening dentinoenamel complex (DEC). Translucent restorative materials offer a significant color measurement challenge as they interact with light in a complex manner that differ than other materials. The old traditional way of visual estimation approaches that solely employ the Munsell color model system based on hue, chroma, and value $(\mathrm{H} / \mathrm{C} / \mathrm{V})$ dominating the dental market seems to be insufficient when allocating the relevant data among the members of the dental team (clinician/technician/patient). ${ }^{(6)}$ In 1931 the Commission Internationale de l'Eclairage (CIE) defined a standard light source, developed a standard observer and enabled the calculation of tri-stimulus $\mathrm{x}, \mathrm{y}, \mathrm{z}$ values, which represent how the human visual system responds to a given colour and allows us to transform spectral energy data into meaningful colour data. It should be noted that the DE in the $\mathrm{L}^{*} \mathrm{a} * \mathrm{~b} *$ colour space indicates the degree of colour difference not the direction of the colour difference. It is often deduced in the literature that a $\Delta \mathrm{E}$ of 1 is the 50:50 perceptibility thresholds. Usually, natural teeth hues have a great tendency to be in the yellow to yellow-orange range which is mainly determined by the colour of dentine while enamel occupying only a slight role through light scattering at the blue range wavelength. ${ }^{(7)}$ Implements used for clinical selection or matching of tooth shade include colourimeters, digital imaging systems and spectrophotometers. ${ }^{(8)}$ It has been previously reported that VITA Easyshade has to be the most 
reliable instrument in both in-vitro and in-vivo researches. ${ }^{(2)}$ Moreover, it has been reported that teeth dehydration can make them appear more whiter by increasing enamel opacity when examined by the Easyshade as the light cannot be scattered from hydroxyapatite crystal to crystal. ${ }^{(6,10,11)}$ This loss of translucency upon dehydration may therefore cause more light reflection that would mask the underlying color of dentine and thus it appears lighter. Russell et al. ${ }^{(12)}$, in their research, applied a rubber dam to the anterior teeth of seven participants and allowed the teeth to dehydrate for $15 \mathrm{~min}$., a measurement was taken using a spectrophotometer and further three more readings were taken at 10 min intervals after removal of rubber dam and tooth rehydration. They revealed that tooth colour had become less saturated and lighter after dehydration and the colour of the teeth reverted to their baseline values $20 \mathrm{~min}$ after removal of the rubber dam. Thus it could be concluded that most dental procedures cause some dehydration of teeth. ${ }^{(13-16)}$

It is crucially required to record the teeth shade at the commencement of the dental appointment but there is insufficient literature evidence to support this. ${ }^{(14)}$ The most commonly reported patient complaint is color mismatch between restoration and natural teeth resulting in restorations replacement consequently increased expense. ${ }^{(2)}$ As most dental procedures can lead to teeth dehydration which in turn can alter their shade resulting in unacceptable results in shade matching. Aiming to elude undesirable mismatch of color between dental restoration and natural teeth it is essential that the procedure of shade selection is carried out at the beginning of the appointment. Thus this clinical trial aimed to investigate any color change in tooth resulting from dehydration resulted from rubber dam application and the required time for color change to recover to baseline and to assess the quality of change and the areas the most affected of the teeth.

\section{MATERIALS AND METHODS}

\section{Research Ethics Committee approval}

This randomized clinical trial was performed at the Clinic of Conservative Dentistry Department, Faculty of dentistry, Cairo university, Egypt with the approval of Research Ethics Committee No. CEBD-2020-4-040. In addition to ClinicalTrials. gov ID of NCT04348773

\section{Consent statement}

An informed consent with an easy Arabic language was signed by the recruited participants.

\section{Sample size calculation}

This power analysis used color change $(\Delta \mathrm{E})$ as the primary outcome. Based upon the results of Suliman S et al (2019); the mean and standard deviation values for $(\Delta \mathrm{E})$ after dehydration and rehydration were $(5.11 \pm 2.39)$ and $(2.73 \pm 2.14)$, respectively. Using alpha $(\alpha)$ level of $(5 \%)$ and Beta ( $\beta$ ) level of $(20 \%)$ i.e. power $=(80 \%)$; the effect size (dz) was found to be (1.046) and the minimum estimated sample size was (10) patients. Sample size calculation was performed using $G^{*}$ Power Version 3.1.9.2.

Ten Participants with intact maxillary central incisors were recruited. Patients were enrolled from the clinic of Conservative Dentistry Department, Cairo University. An informed consent was signed by the recruited participants. The age range was from 20 to 55 years with a mean age of 30.5 years. The inclusion criteria were unrestored intact maxillary central incisors with no tooth bleaching performed during the previous year. Exclusion criteria were presence of any restorations or fixed orthodontic appliance or any fixed retainers on central incisors. After teeth polishing of the recruited participants, they were randomized using computer software. The generated list was then sealed in 10 envelopes by a different person other than the operator. 


\section{Spectrophotometric analysis}

The VITA Easyshade spectrophotometer was used for evaluating tooth shade in this study. After patient acceptance and approval. The Easyshade was used with "Base shade determination" setting to measure colour at middle of the middle third and was calibrated before each set of measurements. To standardize each measurement, a clear vacuumformed template was applied with custom-made window with the same dimension of the VITA Easy-shade probe tip corresponding to the middle of the middle third of the tooth to be assessed. While to ensure infection control, a plastic barrier was applied to the probe tip of the VITA Easyshade. Spectrophotometer measurements for all participants were carried out by the same operator by placing the probe perpendicular to the tooth surface being measured. A baseline measurement was taken of the test tooth. Figure (1A). Then isolated with rubber dam (Nic Tone, medium sheet) and KSK clamp \#210 and allowed to dehydrate without blowing any air from 3 in 1 syringe. Spectrophotometric measurements of the test tooth during dehydration were carried out at $10 \mathrm{~min}$ and $30 \mathrm{~min}$. Figure $(1 \mathrm{~B}, 1 \mathrm{C})$. The rubber dam was then removed and participants were then asked to drink a glass of water. Further spectrophotometric measurements of the test tooth were done at,40 min and $60 \mathrm{~min}$ during rehydration. Figure (1D). Data was collected from the Easyshade as CIE $\mathrm{L}^{*} \mathrm{a} * \mathrm{~b} *$ coordinates, chroma $(\mathrm{C})$, hue $(\mathrm{H})$ and $\Delta \mathrm{E}$.
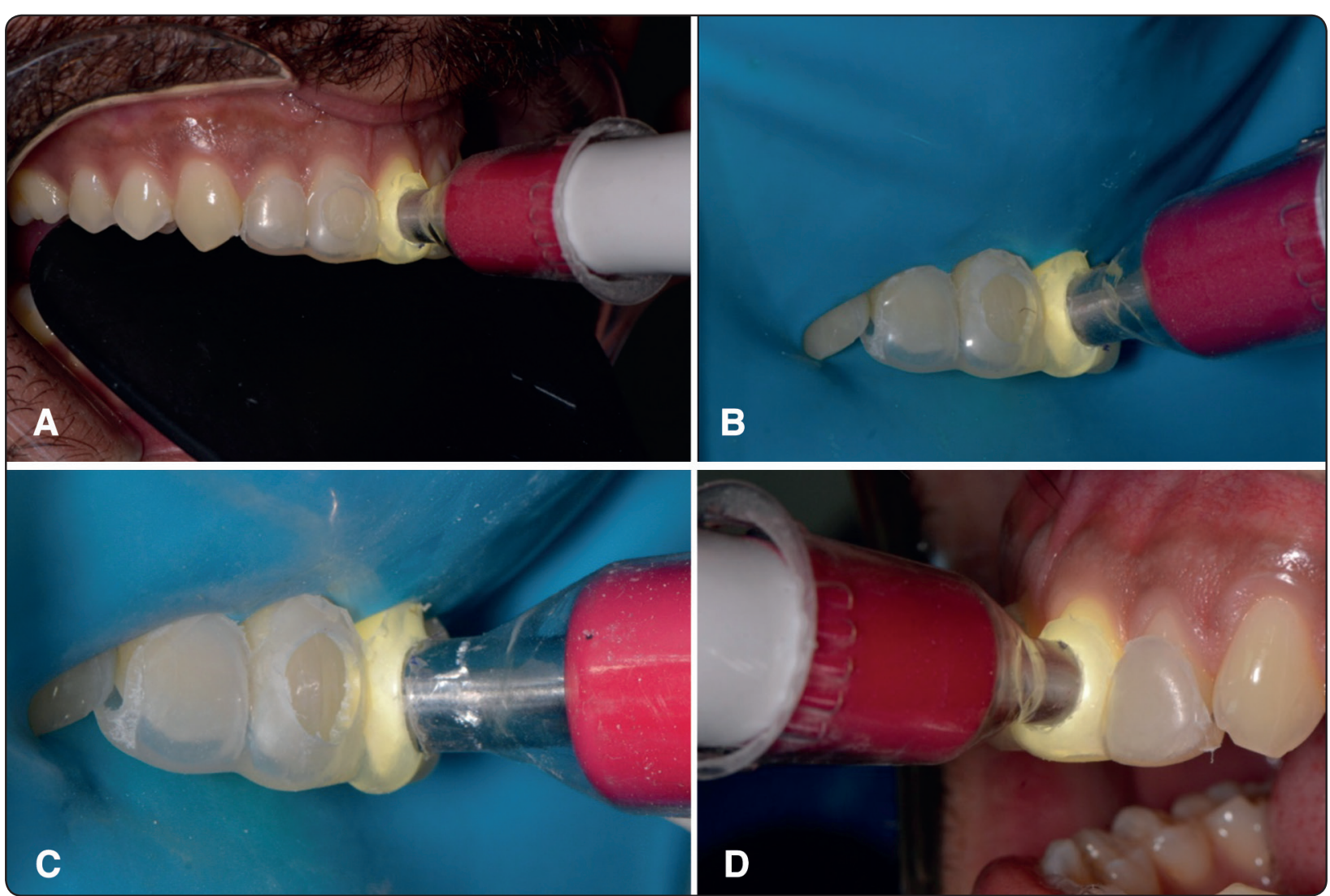

Fig. (1) A: Base line measurement of test tooth, B: Easyshade measurement at 10 min of dehydration, C: Easyshade measurement at $30 \mathrm{~min}$ of dehydration, D: Easyshade measurement at $40 \mathrm{~min}$ of rehydration 


\section{Statistical analysis}

Numerical data were explored for normality by checking the distribution of data and using tests of normality (Kolmogorov-Smirnov and Shapiro-Wilk tests). Color All data showed normal (parametric) distribution except for $\left(\mathrm{a}^{*}\right)$ values which showed non-normal (non-parametric) distribution. Data were presented as mean, standard deviation (SD), 95\% Confidence Interval (95\% CI), median and range values. For parametric data; repeated measures ANOVA was used to study the changes due to deand re-hydration processes. Bonferroni's post-hoc test was used for pair-wise comparisons. For nonparametric data; Friedman's test was used to study the changes due to de- and re-hydration processes. Dunn's test was used for pair-wise comparisons. The significance level was set at $\mathrm{P} \leq 0.05$. Statistical analysis was performed with IBM SPSS Statistics for Windows, Version 23.0. Armonk, NY: IBM Corp.

\section{RESULTS}

\section{Demographic data}

The present study was conducted on 10 teeth in 10 patients; 6 males (60\%) and 4 females (40\%). The mean and standard deviation values for age were 30.5 .

\section{Descriptive statistics of color parameters}

Descriptive statistics of color parameters are presented in Table (1). The mean, standard deviation (SD) values and results of repeated measures ANOVA and Friedman's tests for comparison between color parameters at different time periods (de- and re-hydration) are presented in table (2). The mean, standard deviation (SD) values and results of Friedman's tests for comparison between color change $(\Delta \mathrm{E})$ after de- and re-hydration processes are presented in table (3).

\section{Changes in color parameters after de- and re- hydration:}

$\left(\mathrm{L}^{*}\right)$ value; there was no statistically significant change in mean $\left(\mathrm{L}^{*}\right)$ values after de- and rehydration processes $(\mathrm{P}$-value $=0.108$, Effect size $=$ $0.191)$.

$\left(a^{*}\right)$ value; there was a statistically significant change in mean $\left(\mathrm{a}^{*}\right)$ values after de- and rehydration processes $(\mathrm{P}$-value $=0.009$, Effect size $=0.280)$. Pair-wise comparisons revealed that there was a statistically significant increase in mean $\left(a^{*}\right)$ values after 10 minutes followed by non-statistically significant change from 10 to 30 minutes (A statistically significant increase after dehydration). From 30 to 40 minutes, there was a statistically significant decrease in mean $\left(a^{*}\right)$ value followed by non-statistically significant change from 40 to 60 minutes (A statistically significant decrease after rehydration). The mean ( $\left.\mathrm{a}^{*}\right)$ values after rehydration (40 and 60 minutes) showed nonstatistically significant difference from base line value.

$\left(b^{*}\right)$ value; there was a statistically significant change in mean $\left(b^{*}\right)$ values after de- and rehydration processes (P-value $<0.001$, Effect size $=0.666)$. Pair-wise comparisons revealed that there was a statistically significant increase in mean (b*) values after 10 minutes followed by non-statistically significant change from 10 to 30 minutes (A statistically significant increase after dehydration). From 30 to 40 minutes, there was a statistically significant decrease in mean $\left(b^{*}\right)$ value followed by non-statistically significant change from 40 to 60 minutes (A statistically significant decrease after rehydration). The mean $\left(b^{*}\right)$ values after rehydration (40 and 60 minutes) showed nonstatistically significant difference from base line value.

Chroma value; there was a statistically significant change in mean chroma values after deand re-hydration processes (P-value $<0.001$, Effect 
size $=0.648)$. Pair-wise comparisons revealed that there was a statistically significant increase in mean chroma values after 10 minutes followed by non-statistically significant change from 10 to 30 minutes (A statistically significant increase after dehydration). From 30 to 40 minutes, there was a statistically significant decrease in mean chroma value followed by non-statistically significant change from 40 to 60 minutes (A statistically significant decrease after rehydration). The mean chroma values after rehydration (40 and 60 minutes) showed non-statistically significant difference from base line value.

Table (1). Descriptive statistics of color parameters

\begin{tabular}{|c|c|c|c|c|c|c|c|c|c|}
\hline \multirow{2}{*}{\multicolumn{2}{|c|}{$\begin{array}{c}\text { Time } \\
\text { (minutes) }\end{array}$}} & \multirow{2}{*}{$\begin{array}{c}\text { Color } \\
\text { parameters }\end{array}$} & \multirow{2}{*}{ Mean } & \multirow{2}{*}{ SD } & \multicolumn{2}{|c|}{$95 \% \mathrm{CI}$} & \multirow{2}{*}{ Median } & \multicolumn{2}{|c|}{ Range } \\
\hline & & & & & $\begin{array}{l}\text { Lower } \\
\text { bound }\end{array}$ & $\begin{array}{l}\text { Upper } \\
\text { bound }\end{array}$ & & Minimum & Maximum \\
\hline \multirow{5}{*}{\multicolumn{2}{|c|}{ Base line }} & $\mathrm{L}^{*}$ & 80.6 & 4.6 & 77.7 & 83.6 & 80.5 & 73.3 & 87.7 \\
\hline & & $a^{*}$ & -0.08 & 1.5 & -1.1 & 0.9 & 0.45 & -2.3 & 1.6 \\
\hline & & $\mathrm{b}^{*}$ & 16.8 & 3.1 & 14.8 & 18.8 & 16.9 & 12 & 20.7 \\
\hline & & Chroma & 17 & 3.3 & 14.9 & 19.1 & 17 & 12.1 & 22.7 \\
\hline & & Hue & 94.6 & 3.9 & 92.1 & 97.1 & 95.1 & 88.8 & 100.5 \\
\hline \multirow{12}{*}{ 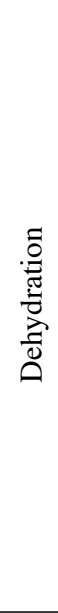 } & \multirow{6}{*}{$\begin{array}{l}\dot{\Xi} \\
\text { ఏ }\end{array}$} & $\mathrm{L}^{*}$ & 82.2 & 2.4 & 80.7 & 83.7 & 82.6 & 77.8 & 85.6 \\
\hline & & $a^{*}$ & 0.2 & 1 & -0.4 & 0.9 & 0.4 & -2 & 1.4 \\
\hline & & $b^{*}$ & 22.2 & 4.4 & 19.4 & 25 & 22.5 & 15.1 & 29.2 \\
\hline & & Chroma & 22.2 & 4.4 & 19.5 & 25 & 22.6 & 15.2 & 29.2 \\
\hline & & Hue & 90.1 & 3.2 & 88.1 & 92.1 & 89.2 & 87.3 & 97.8 \\
\hline & & $\Delta \mathrm{E}$ & 7.3 & 3.9 & 4.8 & 9.7 & 5.9 & 3.1 & 16.3 \\
\hline & \multirow{6}{*}{$\begin{array}{l}\cdot \dot{\Xi} \\
\text { 尺̊ }\end{array}$} & $\mathrm{L}^{*}$ & 82.2 & 1.6 & 81.2 & 83.3 & 82.4 & 79.9 & 85.8 \\
\hline & & $a^{*}$ & 0.4 & 0.9 & -0.2 & 1 & 0.5 & -1.2 & 1.4 \\
\hline & & $b^{*}$ & 23.5 & 3.8 & 21.1 & 25.9 & 23.9 & 17.6 & 29.2 \\
\hline & & Chroma & 23.5 & 3.8 & 21.1 & 26 & 23.9 & 17.6 & 29.2 \\
\hline & & Hue & 89 & 2.2 & 87.7 & 90.4 & 88.8 & 86.7 & 93.7 \\
\hline & & $\Delta \mathrm{E}$ & 8.2 & 3.5 & 6 & 10.5 & 7.1 & 4.7 & 16.3 \\
\hline \multirow{12}{*}{ 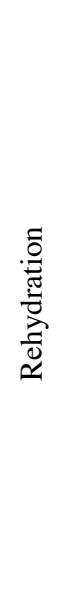 } & \multirow{6}{*}{$\begin{array}{l}\dot{\Xi} \\
\dot{\Xi} \\
\stackrel{+}{+}\end{array}$} & $\mathrm{L}^{*}$ & 83.6 & 1.7 & 82.5 & 84.7 & 84.3 & 80.9 & 85.8 \\
\hline & & $a^{*}$ & -0.3 & 1.2 & -1 & 0.5 & 0.3 & -2.3 & 0.8 \\
\hline & & $b^{*}$ & 19.3 & 3.2 & 17.3 & 21.3 & 19.4 & 13.9 & 23.4 \\
\hline & & Chroma & 19.3 & 3.1 & 17.3 & 21.3 & 19.4 & 14.1 & 23.4 \\
\hline & & Hue & 92.7 & 3.4 & 90.6 & 94.8 & 92.4 & 88.6 & 99.2 \\
\hline & & $\Delta \mathrm{E}$ & 5.5 & 3.1 & 3.5 & 7.4 & 4.2 & 1.6 & 10.9 \\
\hline & \multirow{6}{*}{$\begin{array}{l}\dot{\Xi} \\
\text { ह }\end{array}$} & $\mathrm{L}^{*}$ & 83 & 2.9 & 81.2 & 84.9 & 82.9 & 79.2 & 88.1 \\
\hline & & $a^{*}$ & -0.8 & 1.3 & -1.7 & 0.01 & -1.2 & -2.4 & 1.5 \\
\hline & & $b^{*}$ & 17.5 & 2.9 & 15.7 & 19.3 & 16.6 & 12.9 & 21.7 \\
\hline & & Chroma & 17.6 & 2.8 & 15.8 & 19.3 & 16.7 & 13.1 & 21.7 \\
\hline & & Hue & 95 & 2.8 & 93.2 & 96.7 & 94.5 & 91.4 & 100.4 \\
\hline & & $\Delta \mathrm{E}$ & 4.8 & 2.2 & 3.4 & 6.2 & 4.7 & 1.4 & 8.7 \\
\hline
\end{tabular}


Hue value; there was a statistically significant change in mean hue values after de- and rehydration processes (P-value $<0.001$, Effect size $=0.712)$. Pair-wise comparisons revealed that there was a statistically significant decrease in mean hue values after 10 minutes followed by non-statistically significant change from 10 to 30 minutes (A statistically significant decrease after dehydration). From 30 to 40 minutes, there was a statistically significant increase in mean hue value followed by non-statistically significant change from 40 to 60 minutes (A statistically significant increase after rehydration). The mean hue values after rehydration (40 and 60 minutes) showed nonstatistically significant difference from base line value.

Color change $(\Delta \mathrm{E})$ : there was a statistically significant change in mean $(\Delta \mathrm{E})$ values (P-value $<0.001$, Effect size $=0.602$ ). Pair-wise comparisons revealed that there was no statistically significant change in mean $(\Delta \mathrm{E})$ values from 10 to 30 minutes. From 30 to 40 minutes, there was a statistically significant decrease in mean $(\Delta \mathrm{E})$ value followed by non-statistically significant change from 40 to 60 minutes (A statistically significant decrease after rehydration).

TABLE (2) The mean, standard deviation (SD) values and results of repeated measures ANOVA and Friedman's tests for comparison between color parameters at different time periods (de- and rehydration)

\begin{tabular}{|c|c|c|c|c|c|c|c|c|c|c|c|c|}
\hline \multirow{3}{*}{$\begin{array}{c}\text { Color } \\
\text { parameters }\end{array}$} & \multirow{2}{*}{\multicolumn{2}{|c|}{ Base line }} & \multicolumn{4}{|c|}{ Dehydration } & \multicolumn{4}{|c|}{ Rehydration } & \multirow{3}{*}{$P$-value } & \multirow{3}{*}{$\begin{array}{l}\text { Effect size } \\
\text { (Partial Eta } \\
\text { Squared) }{ }^{\dagger}\end{array}$} \\
\hline & & & \multicolumn{2}{|c|}{$10 \mathrm{~min}}$. & \multicolumn{2}{|c|}{$30 \mathrm{~min}}$. & \multicolumn{2}{|c|}{$40 \mathrm{~min}}$. & \multicolumn{2}{|c|}{$60 \mathrm{~min}}$. & & \\
\hline & Mean & SD & Mean & SD & Mean & SD & Mean & SD & Mean & SD & & \\
\hline $\mathrm{L}^{*}$ & 80.6 & 4.6 & 82.2 & 2.4 & 82.2 & 1.6 & 83.6 & 1.7 & 83 & 2.9 & 0.108 & 0.191 \\
\hline$a^{*}$ & $-0.1^{\mathrm{B}}$ & 1.5 & $0.2^{\mathrm{A}}$ & 1 & $0.4^{\mathrm{A}}$ & 0.9 & $-0.3^{\text {в }}$ & 1.2 & $-0.8^{\mathrm{B}}$ & 1.3 & $0.009 *$ & $r=0.280$ \\
\hline$b^{*}$ & $16.8^{\text {в }}$ & 3.1 & $22.2^{\mathrm{A}}$ & 4.4 & $23.5^{\mathrm{A}}$ & 3.8 & $19.3^{\text {в }}$ & 3.2 & $17.5^{\text {в }}$ & 2.9 & $<0.001 *$ & 0.666 \\
\hline Chroma & $17^{\text {B }}$ & 3.3 & $22.2^{\mathrm{A}}$ & 4.4 & $23.5^{\mathrm{A}}$ & 3.8 & $19.3^{\text {в }}$ & 3.1 & $17.6^{\mathrm{B}}$ & 2.8 & $<0.001 *$ & 0.648 \\
\hline Hue & $94.6^{\mathrm{A}}$ & 3.9 & $90.1^{\text {в }}$ & 3.2 & $89^{\text {в }}$ & 2.2 & $92.7^{\mathrm{A}}$ & 3.4 & $95^{\mathrm{A}}$ & 2.8 & $<0.001 *$ & 0.712 \\
\hline
\end{tabular}

*: Significant at $P \leq 0.05, \dagger$ : Except for $\left(a^{*}\right)$ value where the effect size is $(r)$,

Different superscripts in the same row indicate statistically significant difference

TABLE (3) The mean, standard deviation (SD) values and results of Friedman's tests for comparison between color change $(\Delta \mathrm{E})$ after de- and re-hydration processes

\begin{tabular}{|c|c|c|c|c|c|c|c|c|c|c|}
\hline \multirow{3}{*}{ Color change } & \multicolumn{4}{|c|}{ Dehydration } & \multicolumn{4}{|c|}{ Rehydration } & \multirow{3}{*}{$P$-value } & \multirow{3}{*}{ Effect size (r) } \\
\hline & \multicolumn{2}{|c|}{$10 \mathrm{~min}}$. & \multicolumn{2}{|c|}{$30 \mathrm{~min}}$. & \multicolumn{2}{|c|}{$40 \mathrm{~min}}$. & \multicolumn{2}{|c|}{$60 \mathrm{~min}}$. & & \\
\hline & Mean & SD & Mean & SD & Mean & SD & Mean & SD & & \\
\hline$\Delta \mathbf{E}$ & $7.3^{\mathrm{A}}$ & 3.9 & $8.2^{\mathrm{A}}$ & 3.5 & $5.5^{\text {в }}$ & 3.1 & $4.8^{\text {в }}$ & 2.2 & $<0.001 *$ & 0.602 \\
\hline
\end{tabular}

*: Significant at $P \leq 0.05$, Different superscripts indicate statistically significant difference 


\section{DISCUSSION}

The dynamic light interaction of enamel has revealed to be age related, wavelength specific, and is greatly affected by its hydration condition. ${ }^{(2)}$ Over the last decade, there has been increased interest in alternative photographic techniques aiming to increase the objectivity and accuracy of dental shade evaluation as well as laboratory communication thus minimizing the userdependent error in the future practice. ${ }^{(3)}$ in order to enhance the sensation of surface topography of the maxillary central incisors Direct illumination was used. The reason for observing the time required for teeth rehydration in the present clinical trial was to found whether the resultant color change from dental procedure dehydration could be recovered within a suitable time before accurate measurement of tooth shade. The present clinical trial also evaluated the relative change in shade not the shade itself so it was considered to comprise both central incisors in the same image so that to exclude all concerns that separate images might be affected by other confounders as the environmental lighting, the flash performance and the distance from camera.

In the current study, the results of change in color parameters after de- and re-hydration revealed that $\left(\mathrm{L}^{*}\right)$ value; there was no statistically significant change in mean $\left(\mathrm{L}^{*}\right)$ values after deand re-hydration processes (P-value $=0.108$, Effect size $=0.191)$. However, $\left(a^{*}\right)$ value; there was a statistically significant change in mean $\left(\mathrm{a}^{*}\right)$ values after de- and re-hydration processes ( $\mathrm{P}$-value $=$ 0.009, Effect size $=0.280$ ). Pair-wise comparisons revealed that there was a statistically significant increase in mean $\left(\mathrm{a}^{*}\right)$ values after 10 minutes followed by non-statistically significant change from 10 to 30 minutes (A statistically significant increase after dehydration). From 30 to 40 minutes, there was a statistically significant decrease in mean $\left(a^{*}\right)$ value followed by non-statistically significant change from 40 to 60 minutes (A statistically significant decrease after rehydration). The mean (a*) values after rehydration (40 and 60 minutes) showed non-statistically significant difference from base line value. Furthermore, $\left(b^{*}\right)$ value; there was a statistically significant change in mean $\left(b^{*}\right)$ values after de- and re-hydration processes ( $\mathrm{P}$-value $<0.001$, Effect size $=0.666$ ). Pair-wise comparisons revealed that there was a statistically significant increase in mean $\left(b^{*}\right)$ values after 10 minutes followed by non-statistically significant change from 10 to 30 minutes (A statistically significant increase after dehydration). From 30 to 40 minutes, there was a statistically significant decrease in mean (b*) value followed by non-statistically significant change from 40 to 60 minutes (A statistically significant decrease after rehydration). The mean (b*) values after rehydration (40 and 60 minutes) showed non-statistically significant difference from base line value.

From these results it could be noticed that the major change in color coordinates altered significantly between different time intervals at baseline and $10 \mathrm{~min}$ as well as baseline and 30 min of dehydration resulted from isolation using rubber dam. This was in accordance with Burki et al (2) and it might be attributed to the dehydration effect that results in an increase in the enamel opacity. Tooth dehydration result in creation of new interface in which there was a replacement of the water with air around the enamel prisms resulting in a great alteration in refractive indices with superior scattering at a dehydrated enamel-air interface compared to enamel-water interface. Thus the dehydrated enamel exhibit lower translucency causing more reflection so camouflaging the underlying yellow shade of dentine, that would be interpreted in a lighter appearance. However, this differs from the findings of Russell et al ${ }^{(12)}$ in which only $\mathrm{L}^{*}$ and $\mathrm{a}^{*}$ coordinates were significantly different after dehydration with rubber dam isolation for $15 \mathrm{~min}$. 
In the present study, regarding the Chroma value; there was a statistically significant change in mean chroma values after de- and re-hydration processes (P-value $<0.001$, Effect size $=0.648)$. Pair-wise comparisons revealed that there was a statistically significant increase in mean chroma values after 10 minutes followed by non-statistically significant change from 10 to 30 minutes (A statistically significant increase after dehydration). From 30 to 40 minutes, there was a statistically significant decrease in mean chroma value followed by non-statistically significant change from 40 to 60 minutes (A statistically significant decrease after rehydration). The mean chroma values after rehydration (40 and 60 minutes) showed nonstatistically significant difference from base line value.

For the Hue value; there was a statistically significant change in mean hue values after deand re-hydration processes (P-value $<0.001$, Effect size $=0.712)$. Pair-wise comparisons revealed that there was a statistically significant decrease in mean hue values after 10 minutes followed by non-statistically significant change from 10 to 30 minutes (A statistically significant decrease after dehydration). From 30 to 40 minutes, there was a statistically significant increase in mean hue value followed by non-statistically significant change from 40 to 60 minutes (A statistically significant increase after rehydration). The mean hue values after rehydration (40 and 60 minutes) showed nonstatistically significant difference from base line value. This might be attributed to the alteration in the reflectance spectrum of the dehydrated enamel. ${ }^{(3)}$ These findings are in agreement with previous research where there is an overall gradation in color from the cervical region, which is the most saturated, to the incisal region. ${ }^{(2)}$

Color change $(\Delta \mathrm{E})$ values were calculated to assess the clinical significance of the change in colour measured with spectrophotometer. In the present study, the results of the color change $(\Delta \mathrm{E})$ revealed that there was a statistically significant change in mean $(\Delta \mathrm{E})$ values (P-value $<0.001$, Effect size $=0.602$ ). Pair-wise comparisons revealed that there was no statistically significant change in mean $(\Delta \mathrm{E})$ values from 10 to 30 minutes. From 30 to 40 minutes, there was a statistically significant decrease in mean $(\Delta \mathrm{E})$ value followed by non-statistically significant change from 40 to 60 minutes (A statistically significant decrease after rehydration). This was in accordance with previous studies ${ }^{(2,15,16)}$ where the decrease in translucency during dehydration is described as a consequence of an increased difference in refractive indices between the enamel prisms and the surrounding medium when there is replacement of water by air. Opposite to Russel et al ${ }^{(12)}$ where there was much lower than the present clinical trial, for that reason, there will be high clinical risk to find unacceptable color mismatch between restoration and natural tooth. Thus it could be clinically recommended to wait more than $60 \mathrm{~min}$ for another assessment color match, or much preferably to carry out the color matching procedure on additional appointment.

\section{CONCLUSIONS}

1) It is necessary to develop standardized, reproducible imaging modalities and objective image analysis methods.

2) It should be highlighted that a systematic consideration of the dynamic light interaction within the coronal structures is crucial for selecting proper value and chromaticity for restorative materials that is mandatory to obtain the successful esthetic restorations.

3) Within the restrictions of the present clinical trial, an obvious change in teeth shade was observed upon dehydration that was assessed clinically by spectrophotometer. Thus, it is highly recommended by the clinicians to wait more than $60 \mathrm{~min}$ in order to properly assess color match, or to carry out the shade matching procedure on another dental visit. 
4) Dental shade matching procedures should be performed before the teeth exposure to dehydration to avoid shades mismatch that may not be satisfactory and would require modification or even remake of restorations.

\section{Disclosure of statement}

The authors declare that they have no conflicts of interest

\section{ACKNOWLEDGMENT}

Special thanks to Omar Hesham and Mohamed Aref (resident in conservative dentistry department, faculty of dentistry, Cairo University) for their tremendous efforts and the perfect photographing of the clinical cases in this study.

\section{REFERENCES}

1. Samorodnitzky-Naveh GR, Geiger SB, Levin L. Patients' satisfaction with dental esthetics. The Journal of the American Dental Association 2007;138:805.

2. Burki Z., Watkins S., Wilson R., et al.: A randomised controlled trial to investigate the effects of dehydration on tooth colour.Journal of Dentistry (2013) 41, 250 - 257.

3. Bazos P., Magne P. Bio-Emulation: biomimetically emulating nature utilizing a histo-anatomic approach; visual synthesis. The International Journal Of Esthetic Dentistry, Volume 9, Number 3, Autumn 2014.

4. Hariri I. Estimation of the enamel and dentin mineral content from the refractive index. Caries Res 2013; $47: 18-26$.

5. Hariri I, Sadr A, Shimada Y, et al. Effects of structural orientation of enamel and dentine on light attenuation and local refractive index: an optical coherence tomography study. J Dent 2012;40:387-396.

6. Joiner A. Tooth colour: a review of the literature. Journal of Dentistry 2004;32:3-12.

7. Paul S, Peter A, Pietrobon N, et al.. Visual and spectrophotometric shade analysis of human teeth. Journal of Dental Research 2002;81:578.

8. Brewer JD, Wee A, Seghi R. Advances in color matching. Denta 1 Clinics of North America 2004;48:341.

9. Douglas RD, Steinhauer TJ, Wee AG. Intraoral determination of the tolerance of dentists for perceptibility and acceptability of shade mismatch. TheJournal of Prosthetic Dentistry 2007;97: 200-8.

10. Stevenson B. Current methods of shade matching in dentistry: a review of the supporting literature. Dental Update 2009; 36:270.

11. Dozic A, Kleverlaan CJ, El Zohairy A, et al.. Performance of five commercially available tooth color measuring devices. Journal of Prosthodontics 2007;16: 93-100.

12. Russell M, Gulfraz M, Moss B. In vivo measurement of colour changes in natural teeth. Journal of Oral Rehabilitation 2000;27:786-92.

13. Stevenson B. Current methods of shade matching in dentistry: a review of the supporting literature. Dental Update 2009;36:270.

14. Brewer JD, Wee A, Seghi R. Advances in color matching. Dental Clinics of North America 2004;48:341.

15. Meng Z, Yao XS, Yao H, et al. Measurement of the refractive index of human teeth by optical coherence tomography. J Biomed Opt 2009;14:034010.

16. Suliman S., Sulaiman TA.,Olafsson VG., Delgado AJ., Donovan TE., Heymann HO. : Effect of time on tooth dehydration and rehydration. J Esthet Restor Dent. 2019;1-6. 